KRZYSZTOF M. MAJ

Katedra Technologii Informacyjnych i Mediów Wydział Humanistyczny AGH w Krakowie
Images

vol. XXIX/no. 38

Poznań 2021

ISSN 1731-45OX

\title{
O strukturze świata $w$ narracyjnych grach wideo
}

\begin{abstract}
Maj Krzysztof M., O strukturze świata w narracyjnych grach wideo [On the structure of gameworld in narrative video games]. "Images" vol. XXIX, no. 38. Poznań 2021. Adam Mickiewicz University Press. Pp. 43-55. ISSN 1731-450X. DOI 10.14746/i.2021.38.03.

The article On the structure of gameworld in narrative video games proposes to introduce the term 'ludotopia' to Polish game studies in order to further compartmentalise the structure of video gameworld. Having reflected on the consequences of so-called world-centered turn in contemporary digital humanities, the author proceeds to defining archetypal structures that compose realities designed for the purposes of narrative video games, namely: locations and clusters of locations, the latter divided further into biomes and anthromes. The hierarchy introduced thereby is presented as an alternative for already influential (though, arguably, in transmedial world-building studies rather than game studies) trichotomy of mythos, topos, and ethos, as defined by Lisbeth Klastrup and Susana Tosca. In the end, the article cross-references the new structural hierarchy of ludotopographical components with a matrix of popular fantastic settings, seeking to delineate possible similarities between ludotopias and allotopias that would inform both game scholars and game designers on the ways of rapid prototyping of aesthetically diverse imaginary worlds.
\end{abstract}

KEYwORDS: ludotopia, allotopia, location, biome, anthrome, world-building

Zwrot światocentryczny w kulturze naznaczył medium gier wideo w sposób szczególny[1]. Można wyobrazić sobie proces powstawania powieści, serialu czy filmu bez udziału światotwórstwa, rozumianego jako sztuka tworzenia wyobrażonych światów, ale w grach wideo jest to niemożliwe - $\mathrm{i}$ to $\mathrm{w}$ trzech wymiarach. Po pierwsze, ma ono w tym wypadku wymiar te ch n ol o g i c z n y. Istotną częścią produkcji gry jest projektowanie poziomów (level design), rozpoczynające się od modelowania bryły świata i następnie teksturowania jej tak, by nadać całości estetyczny polor zgodny z określonym założeniem światotwórczym. Po drugie, światotwórstwo ma w nich wymiar lu dolog i c z n y. Niezależnie od tego, czy opiszemy świat gry jako piaskownicę (sandbox), magiczny krąg czy lu d ot o pi ę[2], zawsze w jego realiach możliwa będzie rozgrywka: a więc nie tylko zabawa (rozrywka), lecz

\section{Wprowadzenie}

World, DC Extended Universe itd.)", w zakresie

[1] Zwrot światocentryczny opisuje „[...] ogół przemian w praktykach artystycznych przełomu XX i XXI wieku, znamionujących odejście od rozumienia fikcyjnego świata jako tła dla wydarzeń fabularnych na rzecz dowartościowania jego roli w tworzeniu narracyjnych heterokosmosów oraz rozległych transfikcjonalnych i transmedialnych systemów odniesieniowych, zwanych z racji swej rozległości uniwersami (np. Marvel Cinematic Universe, The Wizarding teorii narracji i literatury natomiast „[...] towarzyszy krytycznej wiwisekcji paradygmatów doby tekstocentryzmu, czyli imperrealizmu oraz werbalnej hegemonii". Por. K.M. Maj, Światotwórstwo w fantastyce. Od przedstawienia do zamieszkiwania, Kraków 2019, s. 58-67, 329-330.

[2] Pojęcie to użyte zostało po raz pierwszy przez redaktorów pracy zbiorowej Ludotopia: Spaces, Places 
także performatyw, który tworzyć będzie pula wszystkich przewidzianych (w przestrzeni gry) i nieprzewidzianych (w przestrzeni metagry) interakcji ze światem. Po trzecie, światotwórstwo w grach wideo ma wymiar narratologiczny, nie jednak w rozumieniu samej sztuki opowiadania historii, ta bowiem ma znaczenie w zakresie fabułotwórstwa (wytyczanie głównej i pobocznych linii fabularnych w grze oraz projektowanie narracji emergentnej), lecz w odniesieniu do projektowania tożsamości narracyjnej gracza zadomawiającego się w allotopii[3] i akomodującego się do jej realiów (topografii, architektury, kultury, sztuki, języka etc.). To właśnie dlatego w grach wideo opowiedzenie historii wymaga wcześniejszego zaprojektowania świata - i jest to wymóg, jak widać, nie tylko techniczny. Nie jest więc przypadkowe rosnące zainteresowanie grami wideo wśród współczesnych teoretyków narracji, rozwijających postklasyczną narratologię w wymiarze transmedialnym[4], a więc nieograniczających się do badania tekstów literackich czy - naznaczonych już w nazwie specyfiką namysłu literaturoznawczego - tekstów kultury, lecz p o n a d medialn y ch (medium-free) zjawisk narracyjnych, takich jak czas, przestrzeń, relacje odniesieniowe czy właśnie świat[5].

Niniejszy tekst podejmuje próbę sproblematyzowania konstrukcji świata w odniesieniu do składających się nań ko mponentów o powtarzalności umożliwiającej wyróżnienie konkretnych archetypów światotwórczych. Allotopijność growych ludotopii czy nawet stopień wysycenia narracji wątkami fantastycznymi nie sprawia bowiem, że mamy do czynienia ze światami całkowicie wykraczającymi poza wzorce poznawcze utrwalone w toku naszego bycia w rzeczywistości, którą uznajemy za realną głównie dlatego, iż jest ona poznawczo pierwotna. Umberto Eco w pierwotnej definicji allotopii założył, że jej cechą dystynktywną jest odmienność strukturalna świata wytworzonego od świata aktualnego[6]. Swoistość tę upatrywał przede wszystkim w dyspozycji narracji allotopijnych do wyznaczania takich wzorców realności, które umożliwiać będą skuteczne zawieszanie niewiary w prawdziwość danej reprezentacji. Prześledzenie sposobów konstrukcji allotopii, niebędące już, niestety, udziałem Eco (problematyzującego pojęcie allo-

and Territories in Computer Games, Espena Aarsetha i Stephana Günzela, na oznaczenie „dialektycznego splątania gry i przestrzeni [dialectical entanglement of game and space]”. E.J. Aarseth, S. Günzel, Introduction. Space - The theoretical frontier, [w:] Ludotopia: Spaces, Places, and Territories in Computer Games, red. E.J. Aarseth, S. Günzel, Bielefeld 2019, s. 7. [3] Allotopia jest światem „[...] innym i fantastycznym, jednakże wykreowanym w wiarygodny sposób tak, aby dla rozpoznania wyróżniającej go cechy fantastyczności nie było konieczne zestawianie świata fantastycznego z rzeczywistym”. K.M. Maj, Światotwórstwo w fantastyce..., s. 322. Por. także: idem, Allotopie. Topografia światów fikcjonalnych, Kraków 2015.
[4] Por. przede wszystkim: Storyworlds Across Media. Toward a Media-Conscious Narratology, red. J.-N. Thon, M.-L. Ryan, Lincoln - London 2014; J.-N. Thon, Transmedial Narratology and Contemporary Media Culture, Lincoln 2016; Narratologia transmedialna: teorie, praktyki, wyzwania, red. K. Kaczmarczyk, Kraków 2017.

[5] M.-L. Ryan, Introduction, [w:] Narrative across Media: The languages of storytelling, red. M.-L. Ryan, Lincoln - London 2004, s. 4.

[6] U. Eco, Po drugiej stronie lustra i inne eseje: znak, reprezentacja, iluzja, obraz, przekł. J. Wajs, Warszawa 2012, s. 235. Por. komentarz w: K.M. Maj, Allotopie..., s. $33-38$. 
topii ledwie zalążkowo), pozwala jednak stwierdzić, że strukturalna odmienność tych światów jest całkowicie pozorna i dotyczy raczej sfery reprezentacji niż samej konstrukcji świata. Problem leży, jak się wydaje, w priorytetach metodologicznych zarówno reprezentowanej przez Eco szkoły semiotyki strukturalnej, jak i rozmaitych orientacji poststrukturalistycznych, które ze strukturalizmem łączy przede wszystkim przekonanie o centralnej pozycji tekstu (w tym także tak zwanego tekstu kultury) w namyśle interpretacyjnym[7]. Najtrwalszym skutkiem tego stało się powiązanie kategorii świata przedstawionego z reprezentacją oraz samą fabułą - w wykładni strukturalnej definiowaną jako jedna z jego „elementarnych jednostek konstrukcyjnych” [8] obok czasu, przestrzeni, postaci czy motywów. Z perspektywy groznawstwa widać bardzo jasno, że podejście to kompletnie rozmija się z intuicjami tak projektantów gier wideo, jak i samych graczy czy badaczy tego medium, traktujących świat raczej jako przestrzeń swobodnej eksploracji niż tło fabularne - i tym samym w odmienny sposób problematyzujących jego elementarne jednostki konstrukcyjne. Z wymienianych przez Janusza Sławińskiego komponentów świata przedstawionego w odniesieniu do allotopii i ludotopii relewantność zachowuje w największym stopniu czasoprzestrzeń i nic dziwnego, że to ona właśnie stała się ośrodkiem refleksji Tomasza Z. Majkowskiego nad gropowieścią i tworzącym ją chronotopem [9]. Postaci, motywy i fabuła w grach wideo budują tymczasem zupełnie inną warstwę doświadczenia artystycznego, nieprzynależącą do swobodnej eksploracji growego świata przynajmniej tak długo, jak długo wciąż od gier z otwartym światem odróżniać będziemy te określane jako interactive movies (wzorcem niech będą tu gry studia Quantic Dream, jak Heavy Rain, Beyond: Two Souls czy Detroit: Become Human). Wyzwanie związane z narratologicznie zorientowanymi badaniami światotwórczymi nad grami wideo zasadza się zatem głównie na konieczności przeniesienia dominanty narracyjnej z paradygmatu tekstocentrycznego na światocentryczny i otwarcia się na refleksję diametralnie odmienną od dotychczasowych priorytetów badawczych literaturoznawstwa, filmoznawstwa i innych dyscyplin inspirujących się założeniami klasycznie zorientowanej teorii narracji.

Odpowiedź na pytanie o to, czym są światy gier wideo (gameworlds), należy rozpocząć od rozważań daleko bardziej podstawowych:

\section{Czym jest świat gry} wideo?
[7] Nawiązuje do tego m.in. Marie-Laure Ryan, zauważając, że „w erze wszechobecnych obrazów, światy fantastyczne okazują się o wiele atrakcyjniejsze od realistycznych. Są produktem wyobraźni, która zbyt długo była już ignorowana przez teoretyków, mających tendencję do uprzywilejowywania talentu pisarskiego kosztem sztuki światotwórczej [„In this age of ubiquitous images, fantasy worlds are visually more attractive than realistic worlds. They are the product of a gift of invention that has too long been ignored by literary critics, who tend to privilege writing skills over the art of world-creation"]. M.-L. Ryan, Why worlds now?, [w:] Revisiting Imaginary Worlds, red. M.J.P. Wolf, London 2016, s. 41.

[8] J. Sławiński, Świat przedstawiony, [w:] Słownik terminów literackich, red. M. Głowiński i in., Wrocław 2005 , s. 565.

[9] T.Z. Majkowski, Grotesque realism and carnality. Bakhtinian inspirations in video game studies, [w:] New Perspectives in Game Studies: Proceedings of the 
Czym w ogóle jest świat? Jak odnotowuje w tekście Why Worlds Now Marie-Laure Ryan, pojęcia tego używano w piśmiennictwie naukowym w trzech podstawowych wykładniach: kosmologicznej, filozoficznej (semantyka możliwych światów) oraz medialno-technologicznej[10]. Czym innym w efekcie jest świat jako ciało niebieskie (które utożsamiamy z Ziemią), czym innym jako część znanego kosmosu, czym innym jako przestrzeń logiczna $\mathrm{z}$ funktorami modalnymi konieczności i możliwości, czym innym jako część znarratywizowanego heterokosmosu, czym innym wreszcie jako immersywne środowisko, w którym jesteśmy zanurzeni niezależnie od tego, czy żyjemy w dwudziestopierwszowiecznej Polsce, w świecie World of Warcraft, czy we śnie, w którym wcielamy się w mysz zamieszkującą gomółkę sera. W przypadku gier wideo produktywne jest mówienie o światach w ostatnim kontekście, zwłaszcza odkąd dane jest nam doświadczać w historii medium „Zwrotu od abstrakcyjnych plansz operujących skonwencjonalizowanymi systemami reguł do otaczającego nas konkretnego świata, w którym możliwe jest wykonywanie symulacji sensownych aktywności [shift from abstract playfield and conventional goals to concrete, surrounding worlds where one performs simulations of meaningful activities]"[11]. Granie w grę możemy dzięki temu potraktować jako synonim bycia-w-świecie-gry - co nie jest oczywistością w odniesieniu do innych mediów przede wszystkim dlatego, że świat ten jest grywalny (playable)[12]. Tak jak każda otaczająca nas rzeczywistość, i ta narzuca nam bowiem różnorodne ograniczenia percepcyjne, kształtuje się pod wpływem naszej woli, dynamicznie reaguje na nasze działania, a także pozwala nam spotykać się z innymi w jego realiach i opowiadać sobie nawzajem historie. Dlatego właśnie nie jest to i nigdy nie będzie świat przedstawiony w rozumieniu strukturalnym - to nie fabuła bowiem powołuje go do istnienia, będąc li tylko zawartością fabular$\mathrm{n}$ ą, opcjonalną aktywnością, której gracz może oddać się w równym stopniu, jak przemierzaniu i eksploracji grajobrazu[13]. O takim świecie najdogodniej więc byłoby mówić jako o lu d ot o p i i: grywalnym, eksplorowalnym i zamieszkiwalnym świecie gry, odpowiadającym w perspektywie fenomenologicznej światowi życia (Lebenswelt), zaś w perspektywie narratologiczno-światotwórczej - allotopii. Ludotopia bowiem w równej mierze mieści ludzkie bycie, zaczynając się i kończąc tam, gdzie zaczyna się i kończy osobniczy horyzont poznawczy, co mimo wszystko pozostaje światem sztucznym, wyobrażonym i fikcyjnym, jednak niemniej przez to rzeczywistym, bo zanurzającym nas

Central and Eastern European Game Studies Conference Brno 2014, red. T. Bártek, J. Miškov, J. Švelch, Brno 2015; idem, Języki gropowieści. Studia o różnojęzyczności gier cyfrowych, Kraków 2019.

[10] M.-L. Ryan, Why Worlds Now?..., s. 34-40.

[11] Ibidem, s. 40.

[12] Ibidem.
[13] Użyteczną tę kontaminację zaproponował Tomasz Z. Majkowski za Shoshaną Magnet na określenie growego krajobrazu „ulegającego przekształceniom na skutek ingerencji gracza”. Zob. T. Majkowski, Pasja kartograficzna. Wyobraźnia imperialna i mapy $w$ grach wideo $z$ otwartym światem, „Kultura Współczesna” 2016, vol. 2, nr 90, s. 34. 
w swych realiach tak długo, jak długo doświadczamy jednego z sześciu opisanych przez Gordona Calleję[14] wymiarów imersji.

To podstawowe założenie ma przy tym tę zaletę, że nie wyklucza możliwości problematyzowania ludotopii w tych wszystkich wymiarach, które przypisuje się światu rzeczywistemu, przedstawianemu i opisywanemu przez ludzkość od wieków w kontekście kosmologicznym, topograficznym, kulturowym, politycznym, metafizycznym, fenomenologicznym, socjologicznym, narratologicznym, historiograficznym, futurologicznym i miriadach pozostałych. Jednocześnie towarzyszące projektowaniu gier wideo w procesie światotwórczym dekonspirowanie fikcyjności świata ma o wiele mniejszy priorytet niż dzieje się to w innych mediach, lubujących się w chwytach parabazy, metafikcji czy deziluzji - i to do tego stopnia, że sprzyjające tym zjawiskom strategie emersyjne, opisane po raz pierwszy przez Piotra Kubińskiego[15], w ostatecznym rozrachunku i tak dążą do wzmożenia imersyjnego doświadczenia bycia-w-innym-świecie[16]. W wypadku ludotopii zatem o wiele produktywniejsze od dywagowania nad statusem fikcjonalnej reprezentacji, referencjalnością czy poetyką (a więc zjawiskami przynależącymi do sfery strukturalnego i poststrukturalnego namysłu nad tekstem) będzie zastanowienie się nad tym, co sprawia, że nawet najbardziej odległe estetycznie założenia światotwórcze (settings) gier współdzielą zauważalne analogie strukturalne w zakresie geografii, klimatu czy architektury (a więc zjawisk przynależących do strukturalnego i poststrukturalnego namysłu nad ś wi a t e m) [17].

[14] Mowa o wymiarach: kinestetycznym (kinesthetic), przestrzennym (spatial), społecznym (shared), narracyjnym (narrative), afektywnym (affective) i ludycznym (ludic). Por. G. Calleja, In-game. From immersion to incorporation, Cambridge - London 2011, s. 55-165.

[15] P. Kubiński, Immersion vs. emersive effects in videogames, [w:] Engaging with Videogames: Play, theo$r y$, and practice, red. D. Stobbart, M. Evans, Leiden 2019, s. 134-135. Por. idem, Emersja - antyiluzyjny wymiar gier wideo, „Nowe Media” 2015, t. 5; idem, Gry wideo. Zarys poetyki, Kraków 2016, s. 69-150.

[16] Zob. K.M. Maj, Światotwórstwo w fantastyce..., S. 292; M. Kłosiński, Hermeneutyka gier wideo. Interpretacja, immersja, utopia, Warszawa 2018, s. 108-112. [17] Praktycznym dowodem tego jest rosnąca liczba narzędzi służących do wspomagania procesu prototypowania, modelowania i teksturowania cyfrowego świata. Wśród najważniejszych należałoby wymienić World Machine (umożliwiający proceduralne generowanie terenu w oparciu o szum Perlina, włącznie z opcjami tworzenia obrysów kontynentów, planowania geologicznie uzasadnionego biegu rzek, modelowania erozji przybrzeżnej, górskiej i termicznej oraz projektowania map wagowych i wysokościowych),
Gaea i Geoglyph (rozszerzenia do narzędzia World Machine, wprowadzające możliwość prototypowania siedmiu rodzajów erozji terenowej, wzorników typów terenów wydmowych, górskich i nizinnych czy teksturowanie fotografii i postprocesowanie gradientów i kolorów na potrzeby mapowania $3 \mathrm{D}$ ), World Creator (umożliwiający rzeźbienie terenu, import i wykorzystywanie map wysokościowych, transformacje rzeźby terenowej - kaniony, góry, wzgórza, płaskowyże, wydmy, także, co ważne, w wariantach allotopijnych zarządzanie biegiem rzek, realistyczne modelowanie erozji terenowej, projektowanie zróżnicowanych biomów roślinności, kontrolę cyklu dnia i nocy czy zarządzanie efektami klimatycznymi) oraz Voxel Studio (oferujące generację biomów roślinności, kontynentów, jezior i oceanów i innych dużych obiektów do swobodnego kształtowania proceduralnego, pakiet podstawowych narzędzi do edycji i modelowania graficznego w $3 \mathrm{D}$ wraz z tworzeniem map wysokościowych, a nawet projektowanie geoprzestrzenne $\mathrm{z}$ wykorzystaniem faktycznych danych geologicznych). Uwagę zwracają również algorytmy światotwórcze na wolnych licencjach, służące proceduralnej generacji realistycznego terenu w rzutach płaskim, izometrycznym i perspektywicznym (Realistic 
Komponenty światotwórcze ludotopii
Nie powstało dotąd zbyt wiele prac naukowych opisujących składniki świata gry - przede wszystkim z uwagi na dominację opisanego już paradygmatu tekstocentrycznego, ale także ze względu na również wspomnianą już rozpiętość znaczeniową świata. Dziś zatem, gdy chcemy mówić o komponentach ludotopii, zwykle musimy poprzestawać na typologii zaproponowanej przez Lisbeth Klastrup i Susanę Tosca przy okazji analizy transmedialnego świata Pieśni Lodu i Ognia, serialowej Gry o tron oraz ich pomniejszej gradaptacji [18]. Wyróżniły one następujące elementy rzeczonego świata:

1) mythos, opisujący czas prehistoryczny fikcyjnej rzeczywistości i sięgający aż do jej kosmogonicznych początków, zwykle zatem aż do narracji założycielskiej;

2) topos, opisujący zmieniającą się w czasie przestrzeń fikcyjnej rzeczywistości, kształtowaną przez składające się na jej historię wydarzenia;

3) ethos, opisujący kształtujące fikcyjną rzeczywistość systemy filozoficzne, religijne i etyczne, które funkcjonują zarówno w wymiarze indywidualnym, jak i uniwersalnym[19].

Jakkolwiek jednak nie sposób odmówić temu podziałowi użyteczności w zakresie transmedialnych badań nad światotwórstwem, w groznawstwie wypada on już dość sztucznie i nie do końca adekwatnie. Horyzont czasowy mythos znacząco wykracza poza chronotop ludotopii i zachowuje zasadność wyłącznie w wąskim zakresie wiedzy o growym świecie (lore), gromadzonej zwykle w znajdowalnych przedmiotach (jak w przypadku książek w The Elder Scrolls V: Skyrim) lub w innego rodzaju diegetycznym leksykonie (jak choćby w rodzaju tego dostępnego w interfejsie pierwszej części serii Mass Effect). Z kolei ethos odnosi się do świata gry w o wiele mniejszym stopniu, niż do rządzących jego prawami wewnątrzgrowych mechanik, jak choćby wykorzystywanej dość powszechnie blokady możliwości krzywdzenia czy zabijania postaci dziecięcych, dwuosiowego systemu charakterologicznego z Dungeons \& Dragons (chaotyczny zły, neutralny zły, praworządny zły, chaotyczny dobry, neutralny dobry, praworządny dobry, chaotyczny neutralny, neutralny, praworządny neutralny), tudzież wyborów moralnych, wpływających najczęściej głównie na przebieg fabularny. W oczywisty sposób najbardziej użyteczny do opisu gier jest topos - lecz paradoksalnie to jemu Klastrup i Tosca poświęcają najmniej uwagi.

Ludotopia w etymologii wskazuje na dwa konstytutywne elementy świata gry: samą rozgrywkę oraz właśnie topos, topografię więc i realia, w których się ona - nomen omen - rozgrywa. Zdefinio- terrain in 130 lines) czy wspomagające proceduralne generowanie map fizycznych z wielokątów w zakresie mapowania obrysów wybrzeży, biegu rzek, biomów roślinności i ogólnej rzeźby terenu (Polygon map generation, opracowany przez studentów Uniwersytetu Stanforda).
[18] Mowa przede wszystkim o grze online The Maester's Path, będącej częścią transmedialnej kampanii marketingowej HBO. L. Klastrup, S. Tosca, Game of Thrones. Transmedial worlds, fandom, and social gaming, [w:] Storyworlds Across Media..., s. 299.

[19] Ibidem, s. 297. 
wanie realiów świata zaś już ze względu na proces produkcyjny gry musi odbywać się na samym początku procesu światotwórczego. Gra osadzona w realiach high fantasy będzie wymagała alokacji o wiele większego budżetu niż ta w świecie nam współczesnym przede wszystkim z uwagi na dostępność gotowych zasobów graficznych, a także wyższą łatwość odwzorowywania rzeczywistości już nam znanej (np. za pośrednictwem fotogrametrii). Z kolei gra projektująca świat futurystyczny w większym stopniu będzie wymagała przywiązywania uwagi do projektu tkanki miejskiej aniżeli obszarów leśnych - co będzie wiązało się także $\mathrm{z}$ wyzwaniem większego zróżnicowania lokacji w celu zapewnienia graczowi wytchnienia od urbanistycznej monotonii. Wszystko to sprawia, że możliwość szybkiego rozeznania konsekwencji światotwórczych wiążących się z wyborem określonych realiów rozgrywki okazuje się pilną potrzebą i to nie tylko w obrębie badań groznawczych.

Najbardziej podstawowym elementem składowym każdego świata gry jest lokacja - i pojęcie to cieszy się też największą popularnością zarówno pośród projektantów gier, jak i samych graczy czy groznawców[20]. Michael Nitsche w książce Video Game Spaces, podobnie zresztą jak przeważająca większość badaczy gier, ogranicza się do funkcjonalnego opisu lokacji, wymieniając ich prototypy w rodzaju toru, korytarza, labiryntu czy areny[21]. Jednak struktury opisywane w ten sposób nie tyle tworzą obraz samej ludotopii, ile raczej rzut perspektywiczny ujawniający architektonikę cyfrowej przestrzeni, projektowanej w taki sposób, by możliwe było uruchamianie w silniku algorytmów odpowiadających chociażby za detekcję kolizji czy wytyczanie ścieżek. Gdy jednak na etapie projektu świata dyskutuje się o tym, jaki świat zostanie zaprojektowany, o wiele częściej myśli się o jego estetyce, dopiero później zaś dostosowuje do jej wymogów układ architektonicznych brył w ramach tak zwanego white box prototype, umożliwiającego wczesną wizualizację układu lokacji i połączeń między nimi[22]. Tymczasem nieprzypadkowo pierwsze komunikaty marketingowe studiów tworzących gry wideo operują właśnie nazwami określonych realiów estetycznych świata, zwykle nazywanych dla uproszczenia settingami. Przykładowo spółka Starward Industries, przygotowująca w chwili

[20] W studiach groznawczych pojęcie lokacji - choć najpopularniejsze - jest tylko jednym $\mathrm{z}$ wielu określających sposób segmentacji grywalnej przestrzeni. José P. Zagal, Clara Fernández-Vara i Michael Mateas wyróżniają także poziomy (levels), mapy (maps) czy fale (waves, tu głównie chodzi o fale wrogów w grach zręcznościowych czy tower defense), co wiąże się też z przyjętym przez nich dość dyskusyjnym modelem traktującym relacje spacjotemporalne na równi $\mathrm{z}$ wyzwaniami rozgrywki (challenges). J.P. Zagal, C. Fernández-Vara, M. Mateas, Rounds, levels, and wa-

\section{Ludotopografia}

ves, „Games and Culture” 2008, t. 3, nr 2, s. 178-179. Por. M. Picard, Levels, [w:] The Routledge Companion to Video Game Studies, red. M.J.P. Wolf, B. Perron, New York 2016, s. 102-105.

[21] M. Nitsche, Video Game Spaces. Image, play, and structure in $3 D$ game worlds, Cambridge - London 2008, s. 172-189.

[22] M. Sturdee i in., Visual methods for the design of shape-changing interfaces [w:] Human-Computer Interaction, red. D. Lamas i in., Cham 2019, s. 337-338. 
pisania tych słów grę wideo opartą na wybranych wątkach z powieści Stanisława Lema, poinformowała o „oprawie retrofuturystycznej” tytułu i stylistyce atompunk[23] - ale już nie o tym, jaki planowana gra będzie oferować typ rozgrywki (RPG, RTS, FPS itd.). Nie powinno to dziwić o tyle, że w 2020 roku CD Projekt Red wydał Cyberpunka 2077, oparłszy całą blisko ośmioletnią komunikację z graczami na efemerycznych skojarzeniach z tytułowym nurtem cyberpunka, podsycanych starannie reżyserowanymi zwiastunami i zapisami liniowej rozgrywki z wczesnej wersji gry, bogato czerpiącymi z estetyki obydwu części filmowego Blade Runnera, anime Ghost in the Shell czy serialu Altered Carbon. Działania takie zdradzają jedno: pierwsze fazy koncepcyjnych prac nad grą wyprzedzają prototypowanie fabuły i mechanik, a nawet detaliczny projekt allotopijnego świata w zakresie kształtowania jego ksenoencyklopedii (lore).

Liczba estetycznych inwariantów założeń światotwórczych jest teoretycznie nieograniczona. Największy problem wiąże się z tym, że większość z nich wykorzystywana jest do wypełniania luk w zakresie genologii narracji fantastycznych i światotwórczych, zaniedbanej przez teoretyków literatury i narracji wskutek braku zainteresowania badaniami w tym zakresie, utożsamionego przez Lindę Hutcheon z konsekwencją długotrwałej dominacji paradygmatu imperrealnego (realist imperialism)[24]. Skutkiem tego takie pojęcia, jak science fiction, high fantasy, low fantasy, heroic fantasy, dark fantasy, military fantasy, steampunk, cyberpunk, atompunk, dieselpunk, biopunk, clockpunk, rococopunk, nowpunk, decopunk, nanopunk, splatterpunk, sandalpunk, contemporary fantasy, space opera, space western, gaslamp fantasy, flintlock fantasy, grimdark fantasy, sword \& sorcery, utopia, dystopia, urban fantasy (fantastyka miejska), romantic fantasy, paranormal romance (romans paranormalny), social science fiction (fantastyka socjologiczna), historical fantasy (fantastyka historyczna), military science fiction używane są w równym stopniu do nazywania form narracyjnych, wyobrażonych światów i stylistyki światotwórczej, co wprowadza dość duży chaos. Racjonalny kompromis nakazywałby więc potraktować przeważającą większość tych pojęć (szczególnie zaś już tych niespełniających rygorów genologicznych, a niekiedy wprost autoironicznych, jak „fantastyka lamp gazowych”) jako określeń ko nwe ncji es tetycznych kształtujących założenie światotwórcze. Rozwią-

[23] StrefaInwestorów.pl, Starward Industries będzie tworzyć gry na podstawie powieści Stanisława Lema. Spółka planuje debiut na NewConnect, <https://strefainwestorow.pl/wiadomosci/20190529/starward-industries-bedzie-tworzyc-gry-na-podstawie-powiesci-stanislawa-lema>, dostęp: 5.01.2021.

[24] Imperrealizm u Hutcheon wyraża się w zakładaniu „realności fikcyjnego referentu, przy tkwiącym $\mathrm{u}$ jego podstaw przekonaniu (apologetycznym względem powieści), że jeśli coś «zdarzyło się naprawdę» lub mogło zostać tak przedstawione, to tym samym się uprawomocniało i uprawdopodabniało”. Według badaczki miało to doprowadzić do utożsamienia w teorii powieści poetyki realistycznej i samego realizmu z gatunkiem fikcji narracyjnej, a w dalszej konsekwencji i do traktowania takiej formy reprezentacji jako wzorcowej (w kontrze do np. poetyki fantastycznej). L. Hutcheon, Metafictional implications for novelistic reference, [w:] On Referring in Literature, red. A. Whiteside, M. Issacharoff, Bloomington 1987, s. 4. 
zanie to wykazałoby przy tym przydatność zarówno w projektowaniu gier wideo, gdzie szczególnie przydatna jest możliwość szybkiego prototypowania spodziewanego wyglądu ludotopii, jak i w samym groznawstwie - i tak borykającym się z koniecznością wieloparametrowego kwalifikowania gatunków gier, uwzględniającego bowiem nie tylko rodzaj wykreowanego w nich świata czy nurt artystyczny, ale i specyfikę wewnątrzgrowej mechaniki. W opisie ludotopograficznym propozycja ta ułatwiałaby natomiast analizę sieci relacji wiążących estetykę danego założenia światotwórczego $\mathrm{z}$ odpowiadającymi mu prototypami lokacji.

Przeważająca większość schematów fabularnych w grach prędzej czy później wymaga skonfrontowania postaci gracza z osobami decyzyjnymi w świecie gry, wysłania go w odległą podróż i przedstawienia wyzwań związanych z przetrwaniem na odludziu lub pospieszenia mu z pomocą na wypadek odniesienia pomniejszych obrażeń. Z tego właśnie względu można dostrzec wyraźne analogie strukturalne między grami reprezentującymi skrajnie różne gatunki i zarazem krańcowo różniącymi się od siebie także pod względem estetyki.

Tabela 1. Realizacje diegetyczne struktury ośrodka władzy w wybranych ludotopiach

\begin{tabular}{|l|l|l|l|}
\hline Tytuł gry & Nazwa lokacji w ludotopii & Nazwa obiektu & Estetyka \\
\hline $\begin{array}{l}\text { Deus Ex: Human Revo- } \\
\text { lution }\end{array}$ & Siedziba Sarif Industries & Wieżowiec & Cyberpunk \\
\hline Assassin's Creed & Laboratorium Abstergo & Biurowiec & $\begin{array}{l}\text { Postindustrialna współ- } \\
\text { czesna }\end{array}$ \\
\hline $\begin{array}{l}\text { Kingdom Come: Delive- } \\
\text { rance }\end{array}$ & Skalica w dolinie Sazawy & Gród & Mediewistyczna \\
\hline XCOM: Enemy Unknown & Baza główna XCOM & $\begin{array}{l}\text { Podziemna } \\
\text { baza operacyjna }\end{array}$ & Futurystyczna \\
\hline Orwell & Program Orwell & $\begin{array}{l}\text { Ekran systemu } \\
\text { inwigilacyjnego }\end{array}$ & Retrofuturystyczna \\
\hline
\end{tabular}

Jak wynika z zestawienia przedstawionego w tabeli 1, sporządzenie kompletnej listy prototypów lokacji odpowiadałoby rozmachem i ambicjami pierwszym projektom strukturalnej szkoły narracji, poczynając od morfologii bajki magicznej Vladimira Proppa, a skończywszy na gramatyce narracyjnej Algirdasa Juliena Greimasa. Interesujące mogłoby być również prześledzenie wpływu empirycznych koordynat czasoprzestrzennych (północ-południe, zachód-wschód), stref klimatycznych (okołobiegunowe, umiarkowane, podzwrotnikowe, zwrotnikowe) oraz związanych z nimi uwarunkowań kulturowo-cywilizacyjnych (industrializacja, nomadyczność, zbieractwo i łowiectwo etc.) na kształtowanie grajobrazu ludotopii - w tym zwłaszcza takich o ambicjach allotopijnych, a mimo to powielających zaznajomione schematy światotwórcze i reprodukujących ziemskie realia fizyczne w pozornie tylko obcym środowisku. 
Od lokacji do biomu i antromu
Same archetypy lokacji nie umożliwiają oczywiście kompletnego zhierarchizowania architektoniki świata gry. Zgrupowane funkcjonalnie pod względem funkcji, jaką pełnią w rozgrywce, posłużą do wyznaczenia obszaru startowego (w którym gracz może spodziewać się podwójnej ekspozycji: nie tylko bowiem przedstawienia reguł gry i mechanik zarządzających ludotopią, lecz także wprowadzenia w realia allotopii), klasterów lokacji mieszczących w sobie obligatoryjną zawartość fabularną i wreszcie wszystkich pozostałych, dostarczających okazji do swobodnej eksploracji i odkrywania aktywności pobocznej. To w obrębie struktur wyższego rzędu zatem wyłania się tak zwany ot warty św iat gry, określający rodzaj na tyle swobodnej organizacji sąsiadujących ze sobą lokacji i wypełniającej je zawartości fabularnej, by stwarzały one iluzję żyjącej rzeczywistości[25]. Otwartość świata nie wiąże się bowiem wyłącznie z brakiem widomych ograniczeń eksploracji, lecz także - a może przede wszystkim - z naturalnym projektem sieci powiązań łączących ze sobą wszystkie lokacje, podporządkowanych w większym stopniu rygorowi realizmu, niż wygodzie rozrywki.

Za najnaturalniejsze określenie struktur ludotopograficznych wyższego rzędu, pozwalających na realistyczną organizację klasterów lokacji, wypada zaś uznać b i o m - także z tego względu, iż pojęcie to przyjęło się już w profesjolekcie projektantów gier i, częściowo, także w socjolekcie graczy. Etymologia biomu naprowadza już od razu na przyjęte na samym początku tego tekstu rozumienie świata. Biom wywodzi się jeszcze z praindoeuropejskiego rdzenia * gwei-, czyli 'żyć, zachowanego w starogreckim ßíoৎ ('życie’), i tym samym sugeruje o wiele wyższy stopień integralności z żyjącym światem gry aniżeli jedynie lokacja. Biomy to bowiem miejsca, w których toczy się życie - ludzi i nieludzi, zwierząt i roślin. Ekologiczne badania nad grami wideo rozróżniają jednakże naturalne biomy od tych naznaczonych ręką ludzką i nazywanych przez to a ntrom a mi (anthromes), czyli biomami antropogenicznymi[26]. To rozróżnienie pozostaje ważne nie tylko z perspektywy kulturowej, ale również światotwórczej - ostatecznie równowaga (lub jej zaburzenie) biomów i antromów niesie ze sobą istotne informacje dotyczące rozwoju danej allotopijnej cywilizacji. Dodatkowo projekt ludotopii wymaga również ciągłej dbałości o urozmaicenie środowiska gry, co stwarza coraz to większe wyzwanie w miarę oddalania się allotopijnej realności od zapoznanych i oswojonych wzorców ziemskich. O wiele trudniejszy jest na przykład do uzyskania balans biomów i antromów w grach futurystycznych - i nic dziwnego
[25] Dużym problemem części polskich prac groznawczych (np. M. Felczak, Sprawczość i tożsamość w grach eksploracyjnych, „Wielogłos” 2015, nr 25; J. Molencki, Trzymać asa w rękawie. Czym jest oszustwo w grach wideo?, „Irydion” 2018, t. 4, $\mathrm{nr}$ 1) jest utożsamianie otwartego świata z gatunkiem gier sandboksowych, które, owszem, charakteryzują się taką konstrukcją świata, lecz - znów - na planie ludologicznym, a nie narratologiczno-światotwórczym (dzięki czemu w grach z serii Grand Theft Auto możliwe jest realizowanie performatywów najdalszych od imersywnych strategii zamieszkiwania świata i gry w zgodzie z realiami ludotopii, czyli tzw. lore-play).

[26] A.Y. Chang, Playing Nature. Ecology in Video Games, Minneapolis 2019, s. 7 . 
zatem, że ich projektanci starają się o pozyskiwanie estetycznych ekwiwalentów ziemskich biomów roślinności pomimo ich pozornie obcego wyglądu (koronnym przykładem będzie tu No Man's Sky, korzystający $\mathrm{z}$ algorytmów do proceduralnego generowania rzeczywistości).

Tabela 2. Najczęściej spotykane biomy i antromy w ludotopiach

\begin{tabular}{|c|c|c|c|}
\hline \multicolumn{2}{|c|}{ Lokacje wyższego rzędu } & Reprezentacje & Gra wideo \\
\hline \multicolumn{4}{|c|}{ Biomy } \\
\hline \multirow[t]{3}{*}{ Pustkowie } & pustynia & Rub' al Khali & Uncharted 3 \\
\hline & pustynia lodowa & Northrend (Azeroth) & World of Warcraft \\
\hline & spalone ziemie & Chaos Wasteland & Warhammer Total War 2 \\
\hline \multirow[t]{3}{*}{ Las } & zwykły las & American Colonial Frontier & Assassin's Creed 3 \\
\hline & zaczarowany las & Czarnylas & Neverwinter Nights \\
\hline & drzewo świata & Teldrassil & World of Warcraft \\
\hline \multirow[t]{2}{*}{ Nizina } & łąka & Reaper's Coast Meadows & Divinity: Original Sin 2 \\
\hline & sawanna & $\begin{array}{l}\text { Postapokaliptyczna Ameryka } \\
\text { Północna }\end{array}$ & Horizon: Zero Dawn \\
\hline Wyżyna & góry & Masyw Druadach & The Elder Scrolls V: Skyrim \\
\hline \multirow[t]{4}{*}{ Akwen } & morze & Zatopiony świat & Oil Rush \\
\hline & archipelag & Skellige & Wiedźmin 3: Dziki gon \\
\hline & podwodne miasto & Rapture & BioShock, BioShock 2 \\
\hline & moczary & Point Lookout & Fallout 3 \\
\hline \multicolumn{4}{|l|}{ Antromy } \\
\hline Osada & wieś & Wyzimskie Podgrodzie & Wiedźmin \\
\hline \multirow[t]{5}{*}{ Miasto } & preindustrialne & City of Cyrodiil & The Elder Scrolls IV: Oblivion \\
\hline & industrialne & City of Dunwall & Dishonored \\
\hline & postindustrialne & Ophir & Technomancer \\
\hline & megamiasto & Night City & Cyberpunk 2020 \\
\hline & ruiny & Villages of Doom & They Are Billions \\
\hline Pustkowie & krajobraz postapokaliptyczny & Postnuklearna Rosja & Metro: Exodus \\
\hline
\end{tabular}

Dążność do równowagi i dywersyfikacji lokacji realizowana jest zatem w grach wideo dwojako. Po pierwsze, archetypowe lokacje kojarzone są z odpowiednimi założeniami światotwórczymi - i tak jak białe bryły w white box prototype zyskują finalny wygląd dzięki nałożeniu odpowiednich tekstur w silniku, tak też rzeczone struktury wzbogacają się o inwarianty dopracowane estetycznie w zgodzie z wybraną przez projektantów stylistyką. Po drugie, klastery tak przygotowanych lokacji łączą się w struktury wyższego rzędu - biomy i antromy - których spójna i wiarygodna reprezentacja wspiera doświadczenie realności i otwartości świata.

Zaproponowany w artykule namysł nad projektowaniem i badaniem ludotopii z wykorzystaniem strukturalnych archetypów i inwariantów różnorodnych założeń światotwórczych świata umożliwiałby zatem szybkie prototypowanie nieoczekiwanych połączeń estetycznych, wspomagające wysiłek kreatywny towarzyszący sztuce światotwórczej.

\section{Zakończenie}


Megamiasto wydaje się na pozór korespondować z estetyką futurystyczną, gdy tymczasem w powieściach Philipa Reeve’a czy w anime Legenda Korry zrealizowane zostaje kolejno w estetyce steampunku oraz low fantasy. Z kolei stepy kojarzą się z nomadycznymi fabułami pikarejskimi, tak częstymi w high fantasy, a tymczasem odżywają w krajobrazie postapokaliptycznym za sprawą serii gier Horizon: Zero Dawn. Krzyżowanie archetypów biomów ze stylami czy konwencjami

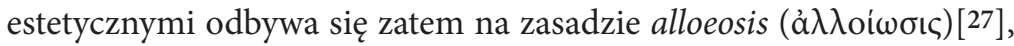
odniesionej metaforycznie w Drzewie i liściu Tolkiena do wizji zielonego słońca, łączącego w sobie znaną nam zieleń i równie znane nam słońce, a mimo to budzącego niepokój, wyobcowanie i defamiliaryzację[28]. A przecież światotwórcza maestria nie zna granic: i tak jak Umberto Eco mógł sobie w Lector in fabula wyobrazić świat, w którym żyją zieleniaki kamieniojady i opisać bazowe warunki sprzyjające wytworzeniu ich habitatu, tak też projektanci gier wideo mogą dowolnie długo łączyć ze sobą pozornie wykluczające się konwencje estetyczne. Lecz to właśnie z podobnych fantazji, by zakończyć słowami Tolkiena, „powstaje nowa forma i rodzi się Królestwo Czarów [Faërie]”[29].

B I B L I O G R A F I A

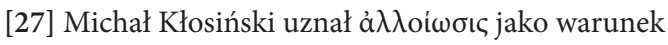
zaistnienia wyobcowującej przestrzeni ( $\alpha \lambda \lambda$ ótpıov) growej allotopii, odnotowując równocześnie jej związek z sytuacją magicznego kręgu, u Johana Huizingi tożsamego $\mathrm{z}$ wyznaczaniem granic rozgrywki. M. Kłosiński, op.cit., s. 158-165.

[28] Jak ujmuje to Tolkien: „Ktokolwiek odziedziczył fantastyczne chwyty mowy ludzkiej, może najzwynr 25, s. $41-51$ 2018 s. $161-176$
Aarseth E.J., Günzel S., Introduction. space - the theoretical frontier, [w:] Ludotopia: Spaces, places, and territories in computer games, red. E.J. Aarseth, S. Günzel, Bielefeld 2019, s. 7-10

Calleja G., In-game. From immersion to incorporation Cambridge - London 2011

Chang A.Y., Playing Nature. Ecology in video games Minneapolis 2019

Eco U., Po drugiej stronie lustra i inne eseje: znak, reprezentacja, iluzja, obraz, przekł. J. Wajs, Warszawa 2012

Felczak M, Sprawczość i tożsamość w grach eksploracyjnych, „Wielogłos” 2015,

Hutcheon L., Metafictional implications for novelistic reference, [w:] On Referring in Literature, red. A. Whitesid, M. Issacharoff MBB437, Bloomington 1987, s. 1-13

Klastrup L., Tosca S., Game of Thrones. Transmedial worlds, fandom, and social gaming, [w:] Storyworlds Across Media: Toward a media-conscious narratology, red. J.-N. Thon, M.-L. Ryan, Lincoln - London 2014, s. 295-314

Kłosiński M., Hermeneutyka gier wideo. Interpretacja, immersja, utopia, Warszawa

Kubiński P., Emersja - antyiluzyjny wymiar gier wideo, „Nowe Media” 2015, t. 5,

Kubiński P., Gry wideo. Zarys poetyki, Kraków 2016

czajniej powiedzieć: «zielone słońce». Potem już wielu może to wyobrazić sobie lub namalować. [...] Powołanie do życia Wtórnego Świata, w którym zielone słońce okaże się wiarygodne i pozyska sobie Wtórną Wiarę, będzie chyba wymagać nie lada wysiłku i myślenia, a na pewno szczególnej biegłości, jakby elfiego rzemiosła". J.R.R. Tolkien, Potwory i krytycy oraz inne eseje, przekł. R. Stiller, Kraków 2010, s. 191.

[29] Ibidem, s. 169. 
Kubiński P., Immersion vs. emersive effects in videogames, [w:] Engaging with Videogames: Play, theory, and practice, red. D. Stobbart, M. Evans, Leiden 2019, s. $133-141$

Maj K.M., Allotopie. Topografia światów fikcjonalnych, Kraków 2015

Maj K.M., Światotwórstwo w fantastyce. Od przedstawienia do zamieszkiwania, Kraków 2019

Majkowski T., Pasja kartograficzna. Wyobraźnia imperialna i mapy w grach wideo z otwartym światem, „Kultura Współczesna” 2016, nr 2 (90), s. 33-44

Majkowski T.Z., Grotesque realism and carnality. Bakhtinian inspirations in video game studies, [w:] New Perspectives in Game Studies: Proceedings of the Central and Eastern European Game Studies Conference Brno 2014, red. T. Bártek, J. Miškov, J. Švelch, Brno 2015, s. 27-43

Majkowski T.Z., Języki gropowieści. Studia o różnojęzyczności gier cyfrowych, Kraków 2019

Molencki J., Trzymać asa w rękawie. Czym jest oszustwo w grach wideo?, „Irydion” 2018 , t. 4 , nr 1, s. $135-150$

Narratologia transmedialna: teorie, praktyki, wyzwania, red. K. Kaczmarczyk, Kraków 2017

Nitsche M., Video Game Spaces. Image, play, and structure in 3d game worlds, Cambridge - London 2008

Picard M., Levels, [w:] The Routledge Companion to Video Game Studies, red. M.J.P. Wolf, B. Perron, New York 2016

Ryan M.-L., Introduction, [w:] Narrative across Media: The languages of storytelling, red. M.-L. Ryan, Lincoln - London 2004

Ryan M.-L., Why worlds now?, [w:] Revisiting Imaginary Worlds, red. M.J.P. Wolf, London 2016, s. 33-43

Sławiński J., Świat przedstawiony, [w:] Słownik terminów literackich, red. M. Głowiński i in., Wrocław 2005, s. 565-566

Starward Industries będzie tworzyć gry na podstawie powieści Stanisława Lema. Spółka planuje debiut na NewConnect, <https://strefainwestorow.pl/wiadomosci/20190529/starward-industries-bedzie-tworzyc-gry-na-podstawie-powiesci-stanislawa-lema>, dostęp: 5.01.2021

Storyworlds Across Media. Toward a Media-Conscious Narratology, red. J.-N. Thon, M.-. Ryan, Lincoln - London 2014

Sturdee M. i in., Visual methods for the design of shape-changing interfaces, [w:] Human-Computer Interaction, red. D. Lamas i in., Cham 2019, s. 337-358

Thon J.-N., Transmedial Narratology and Contemporary Media Culture, Lincoln 2016

Tolkien J.R.R., Potwory i krytycy oraz inne eseje, przekł. R. Stiller, Kraków 2010

Zagal J.P., Fernández-Vara C., Mateas M., Rounds, levels, and waves, „Games and Culture" 2008, t. 3, nr 2, s. 175-198 